cortisol production is a foreboding challenge. Yet, securing the diagnosis is important as untreated Cushing's syndrome carries a high mortality rate. Measurement of a 24 hour urine free cortisol (UFC) is one of the most widely used screening tests for Cushing's syndrome. However, its use in the clinical setting has many shortcomings. There is significant within-patient variability and falsely elevated levels can be seen with over-collection or increased urine volumes. Reported sensitivities up to $95 \%$ are only achieved over 2-3 separate collections, which is logistically difficult for the patient. Furthermore, mild cortisol excess can be missed, a problem particularly in patients with early recurrence of Cushing's disease. In the era of liquid chromatograph/tandem mass spectrometry (LCMS) this is even more of a concern. Often there are subtle excesses of cortisol metabolites in cases of Cushing's syndrome which are included in measurements using traditional radio or immunoassays, but not reported in pure free cortisol measurements in LCMS analyses. However, other testing methods are also fraught with problems, leaving the 24 hour UFC measurement still an important test in the diagnosis and management of Cushing's syndrome.

\section{THE MYTHOLOGY OF VITAMIN D DEFICIENCY AND INSUFFICIENCY}

\author{
Sonali Shah ${ }^{1}$, Cherie Chiang ${ }^{1}$, Ken Sikaris ${ }^{2}$, Ego Seeman $^{1}$ \\ ${ }^{1}$ Departments of Endocrinology and Medicine, Austin Health, \\ University of Melbourne, and ${ }^{2}$ Melbourne Pathology, \\ Melbourne, Vic, Australia
}

Vitamin D deficiency is defined as a serum 25-hydroxy-vitamin $\mathrm{D}(25(\mathrm{OH}) \mathrm{D})$ of less than $30 \mathrm{nmol} / \mathrm{L} .{ }^{1}$ Vitamin D insufficiency is held to be present with values $<75 \mathrm{nM}^{2}$ The aim of this study was to examine the evidence supporting the use of these thresholds as surrogates of bone disease. If valid, then at a level of $25(\mathrm{OH}) \mathrm{D}$ below $30 \mathrm{nM}$, serum PTH and bone remodelling markers should be elevated, bone mineral density (BMD) reduced and microarchitecture deteriorated. Lesser degrees of these abnormalities should be present in persons with values of 25(OH)D between $30-75 \mathrm{nM}$.

We measured serum $25(\mathrm{OH}) \mathrm{D}$, PTH, calcium and creatinine in 10,349 women and 3582 men (using blood samples obtained from Melbourne Pathology). We also critically reviewed the literature dealing with the pathogenesis and treatment of bone disease associated with vitamin D metabolism. Based on the literature, reduced serum 1,25 dihydroxy-vitamin $\mathrm{D}$ and calcium malabsorption was observed only at serum 25(OH)D levels below $10 \mathrm{nM}^{3} \mathrm{We}$ and many other investigators report an inverse association between PTH and 25(OH)D but PTH remained within the reference range in over two-thirds (954/1416) of subjects with $25(\mathrm{OH}) \mathrm{D} \leq 30 \mathrm{nM}$. There was no level $25(\mathrm{OH}) \mathrm{D}$ that distinguished persons with and without secondary hyperparathyroidism. PTH increased with age before and after adjusting for $25(\mathrm{OH}) \mathrm{D}$ and eGFR. The literature revealed little evidence of increased remodelling markers, reduced BMD or microarchitectural deterioration at $25(\mathrm{OH}) \mathrm{D}<30 \mathrm{nM}$ but most studies lacked subjects with 25(OH)D levels below $30 \mathrm{nM}^{4-6}$ Moreover, there was little evidence of hyperosteoidosis in postmortem bone biopsy specimens from 675 deceased patients with serum 25(OH)D $<30 \mathrm{nM}$ (blood taken at death). ${ }^{7}$

The literature confirmed that administration of vitamin D increased serum $25(\mathrm{OH}) \mathrm{D}$ levels but there was little or no improvement in fractional calcium absorption. ${ }^{8}$ Suppression of serum PTH was achieved provided serum $25(\mathrm{OH}) \mathrm{D}$ was below $50 \mathrm{nM} .{ }^{9}$ Whether this is accompanied by reduced remodelling or slowing of bone loss is not known. In one metaanalysis ( $n=4082$ ), fracture risk is reduced by $\sim 8 \%$ when vitamin $\mathrm{D}$ is with calcium, but no benefit when administered alone. ${ }^{10}$

In summary, these null findings may be partly the result of issues in design and execution of the studies. Within these constraints, there is no serum $25(\mathrm{OH}) \mathrm{D}$ level that discriminates persons with and without calcium malabsorption, secondary hyperparathyroidism, deficits in BMD, microarchitectural decay, or evidence of osteomalacia. Nor is there robust replicated evidence of antifracture efficacy of vitamin D supplementation. In conclusion, the scientific basis underlying the choice of these thresholds of vitamin D deficiency and insufficiency, and indications for intervention, are poorly defined. Work is needed to identify surrogates that identify persons with bone disease with high sensitivity and specificity and demonstrate efficacy and safety of vitamin D treatment.

\section{References}

1. Institute of Medicine. Dietary Reference Intakes for Calcium and Vitamin D. Washington, DC: The National Academies Press, 2011.

2. Holick MF, Binkley NC, Bischoff-Ferrari HA, et al. Evaluation, treatment, and prevention of vitamin D deficiency: an Endocrine Society Clinical Practice Guideline. J Clin Endocrinol Metab 2011; 96 : 1911-30.

3. Need AG, O'Loughlin PD, Morris HA, et al. Vitamin D metabolites and calcium absorption in severe vitamin D deficiency. $J$ Bone Miner Res 2008; 23: 1859-63.

4. Mezquita-Raya P, Muñoz-Torres M, Luna JD et al. Relation between vitamin D insufficiency, bone density, and bone metabolism in healthy postmenopausal women. J Bone Miner Res 2001; 16: $1408-15$.

5. Reid IR, Bolland MJ, Grey A. Effects of vitamin D supplements on bone mineral density: a systematic review and meta-analysis. Lancet 2014; 383: 144-56.

6. Boyd SK, Burt LA, Sevick LK, et al. The relationship between serum $25(\mathrm{OH}) \mathrm{D}$ and bone density and microarchitecture as measured by HR-pQCT. Osteoporosis Int 2015; 26: 2375-80.

7. Priemel M, von Domarus C, Klatte TO, et al. Bone mineralization defects and vitamin D deficiency: histomorphometric analysis of iliac crest bone biopsies and circulating 25-hydroxyvitamin D in 675 patients. J Bone Miner Res 2010; 25: 305-12.

8. Bouillon R, Van Schoor NM, Gielen E, et al. Optimal vitamin D status: a critical analysis on the basis of evidence-based medicine. J Clin Endocrinol Metab 2013; 98: 1283-304.

9. Malabanan A, Veronikis IE, Holick MF. Redefining vitamin D insufficiency. Lancet 1998; 351: 805-6.

10. DIPART (Vitamin D Individual Patient Analysis of Randomized Trials) Group. Patient level pooled analysis of 68500 patients from seven major vitamin D fracture trials in US and Europe. BMJ 2010; 340: b5463. 